\title{
The Latest Review of Childhood Obesity among Hispanic and Latinx Populations in California
}

O’Lawrence $\mathrm{H}^{1^{*}}$, Martinez $\mathrm{L}^{1}$, Castelo $\mathrm{G}^{1}$, Humes $\mathrm{E}^{1}$, Mayorga $\mathrm{B}^{1}$, Rosas $\mathrm{S}^{1}$

${ }^{1}$ Health Care Administration, California State University, Long Beach, USA

Corresponding Author: Henry O'Lawrence, Ph.D. ${ }^{\text {ORCID ID }}$

Address: Professor, Health Care Administration, California State University, Long Beach, USA; Email: henry.olawrence@csulb.edu

Received date: 17 April 2020; Accepted date: 23 May 2020; Published date: 02 June 2020

Citation: O’Lawrence H, Martinez L, Castelo G, Humes E, Mayorga B, Rosas S. The Latest Review of Childhood Obesity among Hispanic and Latinx Populations in California. Diab Res Open Access. 2020 Jun 2;2(2):22-30.

Copyright (C) 2020 O'Lawrence H, Martinez L, Castelo G, Humes E, Mayorga B, Rosas S. This is an open-access article distributed under the Creative Commons Attribution License, which permits unrestricted use, distribution, and reproduction in any medium, provided the original work is properly cited.

\begin{abstract}
This research utilizing the data from the California Health Interview Survey (CHIS) (2017) reports on the factors that are linked to childhood obesity among Hispanic/Latinx communities in California with the purpose to determine the causes of the increase in childhood obesity among these two communities. The Statistical Package for Social Sciences (SPSS) was used to determine the significance of the factors that most affect the rate of childhood obesity among Hispanic/Latinx children. The data from CHIS was also utilized to derive categories related to the socioeconomic factors. Frequency tests and a chi-square test on data related to childhood obesity showed that there is a high level of significant differences among the factors that were used in relation to childhood obesity. Overall, it was concluded that there is a significant relationship between childhood obesity and factors that include income, environmental conditions, parent's education, quality of meals, and physical activity.
\end{abstract}

\section{Keywords}

Childhood Obesity, Hispanic/Latinx communities of California, Socio-economic Factors

\section{Introduction}

An increasing number of children are being diagnosed with the condition of obesity and there has been action undertaken to address the issue, however, much more advocacy and action is needed. Advocacy can begin at the state level, such as in the state of California. In the year 2016, the population of children between the ages of o to 11 years in California had a $16.6 \%$ rate of being overweight or obese [1]. When broken down into proportions such as race/ethnicity, American Indians or Alaska Native, and Hispanics were the two largest racial/ethnic groups comprising the percentage of children affected. It is common for minority children to be more at risk for developing health conditions due to factors that include socioeconomic status, education, and environment [2].

According to Sahoo et.al, (2015), "Although the definition of obesity and overweight has changed over time, it can be defined as an excess of body fat" [3]. According to Jin \& Jones-Smith (2015), children that belong to low income families are prone to have less physical fitness and thus a higher chance of developing obesity than children from families with high income. Researchers reached this conclusion in a study where children in the $5^{\text {th }}, 7^{\text {th }}$, and $9^{\text {th }}$ grades took a fitness test and their fitness test results were compared to the students' family income. The study involved eight 
different racial/ethnic groups and Hispanic/Latinx children were among the ones where the income level correlated with the physical fitness level; it also showed the lack of physical fitness among children in Hispanic/Latinx low-income communities which serves as a possible factor that contributes to childhood obesity [4].

Furthermore, about $78 \%$ of Hispanics are overweight due to living in poverty [5]. This can lead to these individuals facing a food shortage and a conflict of not being able to purchase high quality foods. Many researchers predict a scarcity of resources and anxiety often causes Hispanics to purchase low costing foods, which lack nutritional value. Food impoverishment could influence negative eating habits in children, as well as detrimental actions, like binge eating. When children are presented with a lot of food in their home, they are most likely to overeat, as they have a huge amount of food at their fingertips. Most of the time these children lack nutritious foods like fruits and vegetables in their homes which can lead them to binge eat foods that lack nutrients and are full of sugar. Low-income Hispanic families facing food shortages leads to these families not being able to purchase healthy foods, which increases the chances of them developing health problems like obesity [5].

Today, more children are spending an increased time on electronics rather, than engaging in any form of physical activity. In a study conducted on children 8 years old and younger, it was found that children within this age group are spending an average of two hours and 19 minutes with screen media [6]. This means that time is being taken away from physical activity and being given to an activity that offers no health value. Since children are more likely to choose electronic devices over activities that require physical effort, more intervention efforts focusing on physical activity are needed. Children should be encouraged to perform physical activities throughout the day and should be discouraged from turning to electronics for entertainment. Physical activity can be both effective and entertaining for children and meeting these two aspects can result in an increase of effectiveness associated with physical activity. Many children believe that they are physically active, as in a survey asking children how often they exercised, about half reported that they participate in extracurricular activities [7].

The education level of a parent and the information they have regarding nutrition is a factor that plays a role in childhood obesity. According to DeavenportSaman et al. (2019), through the implementation of a multilevel community-academic partnership they developed, they were able to provide culturally sensitive education to parents by teaching them to model healthy eating habits which would result in healthier feeding and parenting behaviors. Furthermore, this partnership included parenting workshops that emphasized nutrition knowledge and behavior change. Most of the parents that participated in this partnership were Latino and 50\% of them had incomes less than $\$ 20,000$. Most of these Latino families that participated came from low-income backgrounds and had little education regarding nutrition which indicates that parent education and income level can have an impact on the likelihood of childhood obesity. This community-academic partnership is a kind of intervention for racial/ethnic minorities that can help address early childhood obesity in underserved families [8].

Furthermore, parents can have an impact on the way their children think about food and nutrition and thus impact the chances of their children becoming obese. According to Giampaoli, Goto, Hart, Yang, and Wylie (2019), mindful food parenting practices are associated with parents providing healthier foods at home for their children and involving them in meal planning activities. Parents that are more aware of what their children are consuming, and their children's eating behaviors, can indirectly impact the health of their children. If more parents had access to nutritional education and were able to learn how to practice mindfulness when feeding their children, it would help to lower obesity rates among children. Encouraging mindfulness in parents may be key in helping parents improve what they feed their children in order to reflect their healthy eating goals [9].

Hispanics in low-income households may depend on help from the government to be able to purchase quality meals. One example of government aid is the 
Supplemental Nutrition Assistance Program (SNAP). This form of government assistance helps families to cover the cost of purchasing healthy foods which they normally may be unable to finance. It is estimated that Latinos encompass more than one-fifth of all SNAP participants [10].

\section{Statement of the Problem}

Childhood obesity has increased in Hispanic and Latinx communities in California. There is no single factor that affects childhood obesity, but instead, an array of factors, such as lack of access to healthy meals, physical activity, nutrition education, and household income. According to Let's Get Healthy California (2016), Hispanic children between ages o to11 years old had a $19.9 \%$ rate of obesity in 2016 , which was a $2.2 \%$ increase from the rate in 2015 , and a $7.2 \%$ increase from the year 2012. It is evident that there is an increasing trend associated with Hispanic childhood obesity rates [1].

Furthermore, childhood obesity is associated with significant health risks like increased risk for high cholesterol, blood pressure, and an array of musculoskeletal disorders [11]. The increase in childhood obesity among children over the years will consequently increase the number of children being diagnosed with these health issues. Although childhood obesity is prevalent among all children, it is disproportionately affecting children of color. Current research suggests that higher rates of obesity are among Latinos, African Americans, and American Indians. Overall, childhood obesity among the Hispanic/Latinx population in California is a problem that is still present in these communities [11].

Obesity is not only linked to a poor diet, but also leads to poor physical activity [12]. If a child is used to eating sweets, and sugary drinks or food, then they are more likely to have a higher BMI, which will lead them to become overweight or obese. Establishing a regular physical activity routine during childhood helps prevent children from developing obesity and related diseases. Physical activity is a factor prominent in this discussion as, "Childhood obesity is related to low physical activity level and a sedentary lifestyle" [13]. Physical activity is what allows our bodies to be exercised effectively and necessary for optimal conduction. If children are not engaging in enough amounts of physical activity, then their bodies lack the proper mechanisms to be healthy. In addition, they may not be able to grow at their full capacity due to a lack of extensibility. As a result, the risk for the onset of obesity or the continuation of it is heightened.

\section{Purpose of the Study}

The purpose of this study was to determine the link between childhood obesity and socioeconomic factors among Hispanic and Latinx communities in California with specific focus on determining the factors, such as environmental conditions, income level, and education that contribute to childhood obesity in Hispanic and Latinx communities. Within these communities, studies show that elevated child body mass index (BMI) has a significant association with neighborhood socioeconomic status and the type of environments these groups live in [14]. Often, childhood obesity goes untreated in minority communities because of the lack of resources and children may carry the condition into adulthood, which can prove detrimental to overall health. The effect of this lack of resources is demonstrated in a study which found that children living in a less environmentally supportive neighborhood had less favorable BMI scores along with higher overweight or obesity rates [15].

\section{Significance of the Study}

It is important to analyze the occurrence of childhood obesity amongst the Hispanic and Latinx community in California. This group is considered a minority, as they comprise a grand portion of the population of the State. In 2014, 15 million Hispanics composed the Californian population as compared to 14.9 million non-Hispanics [16]. By looking at the Hispanic and Latinx population, the cause for the high numbers of obesity can be identified and analyzed. In addition to the population being a significant reason for this study, it is important to place a focus on the children who are being affected by obesity as they are the future of our world. In 2009 - 2010, the National Health and Nutrition Examination Survey reported that $37.9 \%$ of Hispanics and $39.6 \%$ of MexicanAmerican were obese [17]. Since it is much easier to address obesity in childhood than in adulthood, 
identifying the factors that contribute to the occurrence is essential. By knowing how the factors play a role, the appropriate and effective steps to resolve the issue can be taken to prevent further health issues.

The role of neighborhood characteristics and the environment help show racial/ethnic disparities in childhood obesity. Studies show that elevated child body mass index (BMI) has a significant association with neighborhood socioeconomic status and the type of environments these groups live in [14]. The environmental factors analyzed in this study were violent crime, percentage of English speakers, greenness, distance to the nearest highway, physical education, and distance to school. Another study mentioned in the same article, shows the effects of community versus school-based interventions. While community environmental changes were associated to lower the average childhood BMI, mandatory physical education and health programs in school showed far more impact on increased energy expenditures of adolescents [14].

Another environmental factor that has a large impact on childhood obesity is distance and access to primary care. In response to Hispanic/Latino children constituting the greatest percentage $(22.4 \%)$ of the total amount of obese children, the need for primary care intervention has been increasingly called for [18]. Unfortunately, these efforts have had minimal success due to most effective weight management/loss interventions requiring constant communication and rapport with care providers. Most parents believe it is their primary care provider's duty to communicate with them about their child's weight status and to make weight reduction recommendations. Because this essential partnership does not exist for many families within these environments, primary care intervention has not shown significant amounts of success. This is also linked back to the economic effects mentioned earlier, due to Latino children being twice as likely to lack adequate health insurance compared to the white population [18].

According to Saelens et al. (2018), a study conducted to examine 2-year changes in weight and behavior among children living in neighborhoods that differed in nutrition and activity environments showed that the environment is associated with child weight outcomes and behavior changes in children. This study found that children living in less environmentally supportive neighborhoods had less favorable BMI scores along with higher overweight or obesity rates. It was concluded that children in recreation-supportive environments with higher access to nutrition is related to better child weight outcomes and behavior changes. This shows that children being raised in environments with access to high-quality parks and availability of nutritional choices have less chance of experiencing childhood obesity [15].

\section{Research Methodology}

The data set used for this study was obtained from the child questionnaire of the California Health Interview Survey (CHIS) Public Use File and Confidential Data released in September 2017. This survey is conducted annually by multiple entities, which includes the UCLA Center for Health Policy Research, the California Department of Public Health, and the Department of Health Care Services. The questionnaire results were published on August 13, 2018, and the children surveyed through the questionnaire were between the ages of zero to eleven, with the sample size being 1600 children. It is important to mention that the questionnaire was answered by adult proxy respondents of these children.

The Statistical Package for Social Sciences (SPSS) program was used to determine the frequency and chisquare tests on how the categorical data such as income, environmental conditions, parent's education, quality of meals, physical activity, and intervention correlate to childhood obesity. In terms of the frequency test, the number of respondents was taken into consideration to demonstrate how many responses fell under each category and if there were noticeable differences; and the chi-square test was also analyzed to determine the asymptotic significance or better known as the p-value; finally, the hypotheses was tested to either reject or accept as true. 
Citation: O’Lawrence H, Martinez L, Castelo G, Humes E, Mayorga B, Rosas S. The Latest Review of Childhood Obesity among Hispanic and Latinx Populations in California. Diab Res Open Access. 2020 Jun 2;2(2):22-30.

\section{Hypotheses}

\section{First Hypothesis:}

There is no significant relationship between childhood obesity and factors that include income, environmental conditions, parent's education, quality of meals, physical activity, and intervention.

\section{Second Hypothesis:}

There is a significant relationship between childhood obesity and factors that include income, environmental conditions, parent's education, quality of meals, physical activity, and intervention.

\section{Analysis and Results}

In terms of self-reported Latino/Hispanic individuals completing the survey (See table 1 below), 682 of respondents responded yes to identifying with this group. That comprises about $42.6 \%$ of total respondents' Latino/Hispanic. At the same time, 918 respondents out of the 1600 surveyed identify as a group other than Latino/Hispanic. With regards to the question of poverty level, 272 respondents fell under the $0-99 \%$ of federal poverty level (FPL). This means that $17 \%$ of the 1600 total responses fell into this category. Next, between the 100-199\% FPL, 307 of respondents or $19.2 \%$ fell within this classification. The following section of 200-299 \% FPL saw 211 of respondents within this category. In terms of percent, that is $13.2 \%$ of responses. The $300 \% \mathrm{FPL}$ and above saw the highest number of respondents within this category with 810 of individuals falling under this description. The percent of this classification was a $50.6 \%$ of respondents (Table-1).

\begin{tabular}{|l|c|c|}
\hline \multicolumn{2}{|c|}{$\begin{array}{c}\text { Table-1: Respondent on Poverty Level of those } \\
\text { who participated in the study }\end{array}$} \\
\hline $\begin{array}{c}\text { Response (Federal } \\
\text { Poverty level) }\end{array}$ & Frequency & Percent \\
\hline 0-99\% FPL & 272 & $17 \%$ \\
\hline $100-199 \%$ FPL & 307 & $19.20 \%$ \\
\hline $200-299 \%$ FPL & 211 & $13.20 \%$ \\
\hline $300 \%$ FPL \& Above & 810 & $50.60 \%$ \\
\hline Total & $\mathbf{1 6 0 0}$ & $\mathbf{1 0 0} \%$ \\
\hline
\end{tabular}

It should be noted that for the data of Health Professional Concerned That Child Should Be Monitored, 134 of responses or $8.4 \%$ were inapplicable. Only 228 of participants responded yes, and this percent is $14.2 \%$ of the 1600 total. In terms of
"No" responses, 1238 individuals chose this answer and it is $77.4 \%$ of total responses (Table-2).

Table-2: Respondents on Health Professional Concerned that Child Should be Monitored

\begin{tabular}{|c|c|c|}
\hline Response & Frequency & Percent \\
\hline Yes & 228 & $14.20 \%$ \\
\hline No & 1238 & $77.40 \%$ \\
\hline Total & $\mathbf{1 6 0 0}^{*}$ & $\mathbf{1 0 0} \%$ \\
\hline
\end{tabular}

${ }^{*}$ Note: 134 of responses $(8.4 \%)$ where inapplicable for this data set

Due to the large size of this data, it was divided into three sections. These three sections all total up to the 1600 responses. In section A, the response of zero minutes saw 34 participants or $2.1 \%$ of responses choosing this answer. For sitting activities for one minute, there was one response or in percent, . $.1 \%$. Next, two minutes received two responses or .1\%. Four minutes received one response or $.1 \%$. Five minutes was selected by five participants or $.3 \%$. Six minutes was selected by one person (.1\%) while ten minutes was selected by six individuals (.4\%). Next, fifteen minutes was chosen by 8 respondents or $.5 \%$ of individuals and twenty minutes was picked by ten

\begin{tabular}{|c|c|c|}
\hline \multicolumn{3}{|c|}{$\begin{array}{c}\text { Table-3A: Time Doing Sitting Activities (TV, } \\
\text { COMP GAMES, TALK WITH FRIENDS) On } \\
\text { Weekends }\end{array}$} \\
\hline $\begin{array}{c}\text { Response (In } \\
\text { Minutes) }\end{array}$ & Frequency & Percent \\
\hline 0 & 34 & $2.10 \%$ \\
\hline 1 & 1 & $0.10 \%$ \\
\hline 2 & 2 & $0.10 \%$ \\
\hline 4 & 1 & $0.10 \%$ \\
\hline 5 & 5 & $0.30 \%$ \\
\hline 6 & 1 & $0.10 \%$ \\
\hline 10 & 6 & $0.40 \%$ \\
\hline 15 & 8 & $0.50 \%$ \\
\hline 20 & 10 & $0.60 \%$ \\
\hline 30 & 51 & $3.20 \%$ \\
\hline & & \\
\hline
\end{tabular}

respondents or in present, .6\%. Lastly, for this section the option of thirty minutes was selected by 51 
Citation: O’Lawrence H, Martinez L, Castelo G, Humes E, Mayorga B, Rosas S. The Latest Review of Childhood Obesity among Hispanic and Latinx Populations in California. Diab Res Open Access. 2020 Jun 2;2(2):22-30.

Original Article

individuals and in percent this is about 3.2\% (Table3A).

For section B, the first two entries for this section of forty and forty-five minutes indicate the same number of respondents which was 4 individuals each and in percent about . $3 \%$ of total responses. For fifty minutes, only one response was recorded so $.1 \%$. For sixty minutes, there were 204 responses or $12.8 \%$. The ninety-minute response received 36 responses and in percent $2.3 \%$. The next section of one hundred twenty minutes had 351 responses or $21.9 \%$. One hundred fifty minutes saw 10 responses or .6\%. While one hundred eighty minutes received 216 responses or in percent $13.5 \%$. Two hundred ten minutes and two hundred forty minutes each received only 1 response and in percent wise .1\%. Lastly, two hundred forty minutes had 200 participants (12.5\%) that fell under this category (Table-3B).

\begin{tabular}{|c|c|c|}
\hline \multicolumn{3}{|c|}{$\begin{array}{c}\text { Table-3B: Time Doing Sitting Activities (TV, } \\
\text { COMP GAMES, TALK WITH FRIENDS) On } \\
\text { Weekends }\end{array}$} \\
\hline $\begin{array}{c}\text { Response (In } \\
\text { Minutes) }\end{array}$ & Frequency & Percent \\
\hline 40 & 4 & $0.30 \%$ \\
\hline 45 & 4 & $0.30 \%$ \\
\hline 50 & 1 & $0.10 \%$ \\
\hline 60 & 204 & $12.80 \%$ \\
\hline 90 & 36 & $2.30 \%$ \\
\hline 120 & 351 & $21.90 \%$ \\
\hline 150 & 10 & $0.60 \%$ \\
\hline 180 & 216 & $13.50 \%$ \\
\hline 210 & 1 & $0.10 \%$ \\
\hline 240 & 200 & $12.50 \%$ \\
\hline 270 & 1 & $0.10 \%$ \\
\hline & & \\
\hline
\end{tabular}

Please note that 201 (12.6\%) responses were inapplicable for this data. For this last section three hundred minutes received $87(5.4 \%)$ responses. The next section of three hundred sixty minutes received 65 responses or $4.1 \%$ of total responses. With regards to four hundred twenty minutes, 14 respondents (.9\%) chose this. Four hundred eighty minutes saw 35 (2.2\%) participants, while five hundred forty saw only one response (.1\%). Six hundred minutes received 28

\begin{tabular}{|c|c|c|}
\hline \multicolumn{3}{|c|}{$\begin{array}{c}\text { Table-3C: Time Doing Sitting Activities (TV, } \\
\text { WOMP GAMES, TALK WITH FRIENDS) On } \\
\text { Weekends }\end{array}$} \\
\hline $\begin{array}{c}\text { Response (In } \\
\text { Minutes) }\end{array}$ & Frequency & Percent \\
\hline 300 & 87 & $5.40 \%$ \\
\hline 360 & 65 & $.4 .1 \%$ \\
\hline 420 & 14 & $0.90 \%$ \\
\hline 480 & 35 & $2.20 \%$ \\
\hline 540 & 1 & $0.10 \%$ \\
\hline 600 & 28 & $1.80 \%$ \\
\hline 720 & 9 & $0.60 \%$ \\
\hline 780 & 1 & $0.10 \%$ \\
\hline 960 & 4 & $0.30 \%$ \\
\hline 1200 & 3 & $0.20 \%$ \\
\hline 1380 & 1 & $0.10 \%$ \\
\hline 1440 & $160{ }^{*}$ & $10.30 \%$ \\
\hline Total (3A + 3B + 3C) & & $100 \%$ \\
\hline Note: 201 responses (12.6\%) were inapplicable for this \\
\hline
\end{tabular}

(1.8\%) responses and seven hundred twenty received 9 responses or $.6 \%$ or total responses. Seven hundred eighty minutes was chosen by $1(.1 \%)$ while nine hundred sixty minutes received 4 responses (.3\%). One thousand two hundred was selected by three participants $(.2 \%)$, and one thousand three hundred eighty was chosen by 1 (.1\%). Lastly, one thousand four hundred and forty minutes had 4 (.3\%) of responses (Table-3C).

Zero glasses of sweetened fruit drinks drank yesterday was chosen by $975(60.9 \%)$ of the 1600 respondents of this survey. The second largest category was one glass consumed which saw 295 (18.4\%) of total respondents selecting this option. Next was two glasses which received 91 (57\%) of responses. Three glasses of sweetened fruit drink consumed came next with $23(1.4 \%)$ of participants followed by four glasses with $8(.5 \%)$ responses. Then came five glasses with $4(.3 \%)$ of participants and the remaining options of seven, eight, and sixteen glasses each had $1(.1 \%)$ response (Table-4). 
Citation: O’Lawrence H, Martinez L, Castelo G, Humes E, Mayorga B, Rosas S. The Latest Review of Childhood Obesity among Hispanic and Latinx Populations in California. Diab Res Open Access. 2020 Jun 2;2(2):22-30.

Original Article

\begin{tabular}{|c|c|c|}
\hline \multicolumn{3}{|c|}{$\begin{array}{c}\text { Table-4: Number of Glasses of Sweetened Fruit } \\
\text { Drinks Drank }\end{array}$} \\
\hline $\begin{array}{l}\text { Response (In } \\
\text { Minutes) }\end{array}$ & Frequency & Percent \\
\hline o & 975 & $60.90 \%$ \\
\hline 1 & 295 & $18.40 \%$ \\
\hline 2 & 91 & $5.70 \%$ \\
\hline 3 & 23 & $1.40 \%$ \\
\hline 4 & 8 & $0.50 \%$ \\
\hline 5 & 4 & $0.30 \%$ \\
\hline 7 & 1 & $0.10 \%$ \\
\hline 8 & 1 & $0.10 \%$ \\
\hline 16 & 1 & $0.10 \%$ \\
\hline Total & $1600^{*}$ & $100 \%$ \\
\hline *Note: 201 & responses & pplicable. \\
\hline
\end{tabular}

In terms of adult educational attainment, 92 out of 1600 adults or $5.8 \%$ responded that they had no formal education or only completed grades $1-8$. Second, only 87 (5.4\%) of adults responded that they attended grades $9-11$. Furthermore, 327 or $20.4 \%$ of

\begin{tabular}{|l|c|c|}
\hline \multicolumn{3}{|c|}{$\begin{array}{r}\text { Table-5: Time Doing Sitting Activities (TV, } \\
\text { COMP GAMES, TALK WITH FRIENDS) On } \\
\text { Weekends }\end{array}$} \\
\hline Response (In Minutes) & Frequency & Percent \\
\hline $\begin{array}{l}\text { No formal education or } \\
\text { grades 1-8 }\end{array}$ & 92 & $5.80 \%$ \\
\hline Grades 9-11 & 87 & $5.40 \%$ \\
\hline Grade 12/H.S. diploma & 327 & $20.40 \%$ \\
\hline Some College & 169 & $10.60 \%$ \\
\hline $\begin{array}{l}\text { A.A./A.S. degree or } \\
\text { Vocational School }\end{array}$ & 177 & $11.10 \%$ \\
\hline $\begin{array}{l}\text { B.A. or B.S. degree/ Some } \\
\text { grad school }\end{array}$ & 423 & $26.40 \%$ \\
\hline M.A. or M.S. degree & 204 & $12.80 \%$ \\
\hline Ph.D. or equivalent & 121 & $7.60 \%$ \\
\hline Total & $\mathbf{1 6 0 0}$ & $\mathbf{1 0 0} \%$ \\
\hline
\end{tabular}

adults completed grade 12 and obtained a high school diploma. Out of 1600 adults, 169 (10.6\%) completed some college. In addition, 177 (11.1\%) adults had an
AA/AS degree or attended a vocational school. Moreover, 423 out of 1600 adults or $26.4 \%$ had a BA or BS degree or completed some grad school. There were $204(12.8 \%)$ adults that responded that they had a MA or MS degree. Lastly, only 121 (7.6\%) adults had a Ph.D. or equivalent (Table-5).

Regarding the question about a park/playground within 30-minutes walking distance from home, 94 out of 1600 respondents or $5.9 \%$ stated this was inapplicable to them. Next, 1383 (86.4\%) responded yes, meaning there was a park or playground within 30-minutes from their home. Lastly, 123 (7.7\%) responded no, meaning there was not a park or playground within 30-minutes from their home.

A Chi-Square test was conducted to determine independence of Hispanic/Latinx answers with each other variable. For the park/playground within 30 minutes walking distance of the home variable, there was a Chi-square value of 2.930, a $d f$ of 2 , and an Asymp. Sig. of .231. Adult educational attainment had a Chi-square value of 269.289, a df of 7, and an Asymp. Sig. of .ooo. Number of glasses of sweetened fruit drinks drank yesterday Chi-square value was 10.906, a $d f$ of 9, and an Asymp. Sig. of .282. Next, the time doing sitting activities category had a Chi-square value of 30.499, a $d f$ of 31, and an Asymp. Sig. of .492. In addition, health professional concerned that the child should be monitored had a Chi-square value of 11.819, a $d f$ of 2, and an Asymp. Sig. of .oo3. Poverty level had

\begin{tabular}{|l|c|c|c|}
\hline \multicolumn{4}{|c|}{ Table-6: Chi Square test } \\
\hline \multicolumn{1}{|c|}{ Responses } & $\begin{array}{c}\text { Chi } \\
\text { Square }\end{array}$ & df & $\begin{array}{c}\text { Asymp } \\
\text {. Sig. }\end{array}$ \\
\hline $\begin{array}{l}\text { Park/playground within } \\
\text { 30 min walking distance } \\
\text { of the home }\end{array}$ & 2.93 & 2 & 0.231 \\
\hline $\begin{array}{l}\text { Adult educational } \\
\text { attainment }\end{array}$ & 269.289 & 7 & 0 \\
\hline $\begin{array}{l}\text { \# of glasses of sweetened } \\
\text { Fruit drinks drank }\end{array}$ & 10.906 & 9 & 0.282 \\
\hline $\begin{array}{l}\text { Time doing sitting } \\
\text { activities }\end{array}$ & 30.499 & 31 & 0.492 \\
\hline $\begin{array}{l}\text { Health professional } \\
\text { Concerned that the Child } \\
\text { should be monitored }\end{array}$ & 11.819 & 2 & 0.003 \\
\hline Poverty level & 197.927 & 3 & 0 \\
\hline
\end{tabular}


Chi-square value of 197.927, a $d f$ of 3 , and an Asymp. Sig. of .ooo (Table-6).

\section{Summary and Conclusion}

Childhood obesity is a recurring issue occurring in the state of California. There are numerous factors that affect this disease and its occurrence, such as those included in this paper. From this research study, it is shown that there is a significant relationship between childhood obesity and certain factors that include income, environmental conditions, parent's education, quality of meals, physical activity, and intervention. By finding the association between Hispanic/Latinx respondents and the obesity linked factors, we find this group of the Californian population is more exposed to obesity causing characteristics. Since it is known that these factors contribute to childhood obesity, more priority can be given to address these issues and lessen its effect. In conclusion, by taking the proper steps to prevent childhood obesity, more children can live healthier and longer lives in California.

In order to see which hypothesis is to be accepted and which is to be rejected, a discussion of the data is needed. The two tests ran were the frequency test and the chi-square test with the following factors:

- Self-reported Latino/Hispanic

- Poverty level

- Health professional concerned that the child should be monitored

- Time doing sitting activities

- \# of glasses of sweetened fruit drinks drank

- Adult educational attainment

- Park/playground within 30 min walking distance of the home

In terms of the frequency tests data, the selfreported Latino category received 918 or $57.4 \%$ of responses as no. In the poverty factor, 810 respondents selected the classification of the $300 \%$ federal poverty level which in percent wise is equivalent to $50.6 \%$. This means that half of respondents were classified as $300 \%$ of the poverty line for this year which signifies poverty level.

With regards to healthcare professionals being concerned that children should be monitored, 1238 or
$77.4 \%$ of respondents elected no as their response. Time doing sitting activities on weekends is significant as the choice of 120 minutes was selected by 351 respondents or $21.9 \%$ of the 1600 participants of the survey. The 120 minutes is equivalent to two hours being spent on activities such as watching tv which is time being taken away from physical activity. In terms of sugary drinks consumed, there was no major significance as $60.9 \%$ or 975 of respondents selected o glasses. Adult educational attainment saw the largest amount of responses under the BA or BS degree/ Some Grad School category with 423 or $26.4 \%$ of responses. Lastly, with the question of park/playground within 30 minutes walking distance of home, 1383 of individuals or $86.4 \%$ elected yes as their answer.

In terms of chi-square data, the categories that have a $p$-value < .05 include adult education obtainment, health professional concerned child should be monitored, and poverty level which signifies that they have a high level of significance. This is considered a high level of significance as any range less than .05 is considered significant according to Chi-Square guidelines. Based on these results, the second hypothesis for these variables is determined to be true while the first hypothesis is rejected. The other variables with a $p$-value $>.05$, cannot be associated to Hispanic respondents of the questionnaire.

\section{References}

[1] Let's Get Healthy California. Obese youth are at greater risk for health problems, including type 2 diabetes, high blood pressure, asthma, early maturation, and joint problems. 2016. Available from: https://letsgethealthy.ca.gov/goals/healthybeginnings/reducing-childhood-obesity/

[2] Minority Health. National Institute of Allergy and Infectious Diseases. 2018. Available from: https://www.niaid.nih.gov/research/minority-health [3] Sahoo K, Sahoo B, Choudhury AK, Sofi NY, Kumar R, Bhadoria AS. Childhood obesity: causes and consequences. J Family Med Prim Care. 2015 AprJun;4(2):187-92. [PMID: 25949965]

[4] Jin Y, Jones-Smith JC. Associations between family income and children's physical fitness and obesity in California, 2010-2012. Prev Chronic Dis. 2015 May 14;12:140392. 
[5] Smith TM, Colón-Ramos U, Pinard CA, Yaroch AL. Household food insecurity as a determinant of overweight and obesity among low-income Hispanic subgroups: Data from the 2011-2012 California Health Interview Survey. Appetite. 2016 Feb 1;97:37-42. [PMID: 26603573]

[6] Howard J. Kids under 9 spend more than 2 hours a day on screens, report shows. CNN; 2017 Oct 19. Available from:

https://www.cnn.com/2017/10/19/health/childrensmartphone-tablet-use-report/index.html

[7] Bishop W, Chavarin C, Gonzales HA, Iparraguirre J, Mann J, Specker S, Linton KF. Healthy eating and physical activity among low-income Hispanic adolescents and a school-based intervention. Children and Youth Services Review. 2018 Feb;86:151-56.

[8] Deavenport-Saman A, Piridzhanyan A, Solomon O, Phillips Z, Kuo T, Yin L. Early Childhood Obesity Among Underserved Families: A Multilevel Community-Academic Partnership. Am J Public Health. 2019 Apr;109(4):593-96. [PMID: 30789762]

[9] Giampaoli J, Goto K, Hart SR, Yang S, Wylie A. Factors Associated with Mindful Food Parenting Practices. Californian Journal of Health Promotion. 2019 Jun 1;17(1):45-6o.

[10] Center on Budget and Policy Priorities. SNAP helps millions of Latinos; 2018. Available from: https://www.cbpp.org/research/food-assistance/snaphelps-millions-of-latinos

[11] Babey SH, Wolstein J, Diamant AL, Bloom A, Goldstein H. Overweight and obesity among children by California cities-2010. UCLA Center for Health Policy Research and California Center for Public Health Advocacy. 2012 Jun 1:1-8.

[12] Fakhouri TH, Hughes JP, Brody DJ, Kit BK, Ogden CL. Physical activity and screen-time viewing among elementary school-aged children in the United States from 2009 to 2010. JAMA Pediatr. 2013 Mar 1;167(3):223-29. [PMID: 23303439]

[13] Lee ST, Wong JE, Shanita SN, Ismail MN, Deurenberg P, Poh BK. Daily physical activity and screen time, but not other sedentary activities, are associated with measures of obesity during childhood. Int J Environ Res Public Health. 2014 Dec 23;12(1):14661. [PMID: 25546277]

[14] Sharifi M, Sequist TD, Rifas-Shiman SL, Melly SJ, Duncan DT, Horan CM, Smith RL, Marshall R, Tavera

EM. The role of neighborhood characteristics and the built environment in understanding racial/ethnic disparities in childhood obesity. Prev Med. 2016 Oct;91:103-109. [PMID: 27404577]

[15] Saelens BE, Glanz K, Frank LD, Couch SC, Zhou C, Colburn T, Sallis JF. Two-Year Changes in Child Weight Status, Diet, and Activity by Neighborhood Nutrition and Physical Activity Environment. Obesity (Silver Spring). 2018 Aug;26(8):1338-46. [PMID: 30138547]

[16] Reese P, Magagnini S. Census: Hispanics Overtake Whites to Become California's Largest Ethnic Group. The Sacramento Bee. 2015 Jun 30. Available from: https://www.sacbee.com/news/local/article25940218. html

[17] Cruz Y, Hernandez-Lane ME, Cohello JI, Bautista CT. The effectiveness of a community health program in improving diabetes knowledge in the Hispanic population: Salud y Bienestar (Health and Wellness). J Community Health. 2013 Dec;38(6):1124-31. [PMID: 23913103]

[18] Gonzalez G. Primary Care Interventions to Reduce Childhood Obesity in Latino Families. J Pediatr Health Care. 2016 Sep-Oct;30(5):471-79. [PMID: 26677979] 